\title{
GURU BERPRESTASI SUMBER DAYA MANUSIA PENGEMBANG MUTU PENDIDIKAN INDONESIA
}

\author{
Rusi Rusmiati Aliyyah ${ }^{1}$, Widyasari ${ }^{2}$, Didi Mulyadi ${ }^{3}$, \\ Sri Wahyuni Ulfah ${ }^{4}$, Siti Rahmah ${ }^{5}$ \\ Universitas Djuanda Bogor, Jawa Barat, Indonesia ${ }^{1,2,4,5}$ \\ Sekolah Tinggi Ilmu Ekonomi Pertiwi Bekasi, Jawa Barat, Indonesia ${ }^{3}$ \\ rusi.rusmiati@unida.ac.id ${ }^{1}$
}

\begin{abstract}
ABSTRAK
Penelitian bertujuan untuk mendeskripsikan proses seleksi dan pembinaan yang diberikan kepada guru berprestasi tingkat nasional pada SD Al Irsyad Al Islamiyyah Bekasi Jawa Barat. Menggunakan pendekatan kualitatif dengan metode studi kasus. Data dikumpulkan melalui observasi, wawancara dan dokumentasi. Teknik analisis data menggunakan reduksi data, penyajian data, dan penarikan kesimpulan. Hasil penelitian menyatakan bahwa seleksi guru berprestasi dilakukan secara berjenjang dimulai dari tingkat satuan pendidikan, kecamatan, kabupaten/kotamadya, provinsi dan nasional. Seleksi guru berprestasi terdiri dari seleksi akademik, administratif dan seleksi persyaratan khusus. Simpulan, calon guru berprestasi diberikan pembinaan dan pelatihan oleh stakeholders pendidikan mulai dari kepala sekolah pada satuan pendidikan, KKG, dinas pendidikan, pemerintah daerah, pengawas, LPMP, Perguruan Tinggi, dan P4TK.
\end{abstract}

Kata Kunci: Seleksi, Pembinaan, Guru Berprestasi

\begin{abstract}
The purpose of this research is to describe the selection and process coaching that is given to outstanding national-level teachers at Al Irsyad Al Islamiyyah Bekasi West Java. Using approach qualitative with the case study method. Data collected through observation, interviews and documentation. Data analysis techniques data using reduction, data presentation, and concluding. The results of the study stated that the selection of outstanding teachers was carried out in stages starting from the level of the education unit, sub-district, levels district/municipality, provincial and national. Conclusion, outstanding teacher selection consists of academic, administrative and special requirements. Prospective teachers are given guidance and training by education stakeholders ranging from school principals in units education, $K K G$, education offices, local government, supervisors, LPMP, Higher Education, and P4TK.
\end{abstract}

Keywords: Selection, Guidance, Outstanding Teachers 


\section{PENDAHULUAN}

Kondisi bangsa Indonesia yang semakinmengarah pada persaingan ilmu pengetahuan tentu menuntut sumber daya manusia yang handal yang mampu berkompetensi dalam membentuk ilmu pengetahuan dalam sumber daya baru. Tantangan lembaga pedidikandalam menentukan sumber daya manusia yang mampu memberikan dampak positif terhadap pengetahuan pada proses pendidikan yang dilaksanakan secara profesionalis guru. Upaya peningkatan sumber daya manusia suatu keharusan bangsa Indonesia pada era globalisasi yang menuntut kesiapan setiap bangsa untuk saling bersaing secara bebas. Oleh karena itu, pemerintah melakukan salah satu upaya proritas pembangunan dalam pendidikan(Kompri, 2015). Sementara itu, pendidikan di sekolah tidak terlepas dari sosok seorang guru yang berperan sebagai informator, inspirator, korektor, organisator, fasilitator di kelas (Syahputra, Lubis, \& Windarto 2018).

Guru merupakan salah satu faktor utama yang menentukan mutu pendidikan. Untuk menciptakan mutu pendidikan yang baik dibutuhkan kinerja yang baik pula dari guru dalam menjalankan tugasnya secara profesional. Kinerja guru merupakan kemampuan yang ditunjukkan dalam melaksanakan tugas sesuai tanggung jawab yang dibebankan(Syifa, et.al, 2016). Dalam hal ini kompetensi guru juga sangat penting mengenai hubungan dengan kegiatan dan hasil belajar siswa. Guru yang kompoten mampu mengelola kelasnya secara optimal (Mustari, 2014).

Dengan demikian, dunia pendidikan akan membawa kemajuan bagi bangsa dan negara Indonesia.Dalam pelaksanaan guru berprestasi pemerintah merencakan seleksi dalam proses pemilihan individu-individu yang memiliki kualifikasi yang relevan untuk mengisi pekerjaan-pekerjaan dalam suatu organisasi. Jenis-jenis seleksi diantaranya seleksi administrasi, seleksi tertulis, dan seleksi tidak tertulis (Samuel, 2017).

Pelaksanaan guru prestasi tidak terpisah dari peran stackholder. Karena stakholder adalah bagian penting dari sebuah organisasi yang memiliki peran secara aktif maupun pasif untuk mengembangkan tujuan dalam pendidikan, setiap instansi atau tingkat Dinas Pendidikan. Begitupun peran kepala sekolah harus dapat mendorong kinerja para guru dengan menunjukan rasa bersahabat, dekat, dan penuh pertimbangan terhadap para guru, baik sebagai individu maupun sebagai kelompok(Inayatillah, et.al, 2016). Klasifikasi stakeholder dalam dunia pendidikan terdiri dari Kepala Sekolah, Peran Pemerintah Daerah (Dinas Pendidikan Kecamatan, Kabupaten/Kota, Provinsi, LPMP, Pusat Pengembangan dan Pemberdayaan Pendidik dan Tenaga Kependidikan.

Upaya untuk mendapatkan sebuah penghargaan dan predikat guru berprestasi atau guru profesional bukanlah hal yang mudah. Untuk mencapai tujuan tersebut dibutuhkan usaha, kesiapan dan juga pelatihan serta pembinaan yang diberikan oleh stakholder kepada guru-guru.Oleh karena itu guru harus 
melakukan upaya pembinaan berkelanjutan agar fungsi-fungsi keguruan berjalan secara optimal(Sauri, 2010).

Oleh karena itu, seleksi merupakan langkah awal ketika kita akan memulai sesuatu. Tak terkecuali dengan pembahasan pada kali ini. Telah kita singgung sebelumnya, salah satu penunjang yang harus dilakukan untuk mendapatkan guru berprestasi ialah kualitas serta kompetensi yang dimiliki oleh SDM serta peran stakholder dalam pembinaan dan pelatihan guru berprestasi.

SD Al Irsyad Al Islamiyyah merupakan salah satu Sekolah Dasar Swasta yang maju prestasinya dalam bidang akademik maupun non-akademik. Keberhasilan yang diraih oleh SD Al Irsyad Al Islamiyyah karena prestasi dan mutu pendidikan yang baik sehingga dapat menjadikan sekolahnya menjadi nomor satu di Bekasi Barat. Untuk mencapai keberhasilan dan meningkatkan mutu pendidikan, sekolah membutuhkan SDM yang berkompeten dan memiliki keahlian khusus dibidangnya masing-masing. Meningkatkan mutu pendidikan dari SD tersebut salah satunya karena baiknya kualitas guru yang ada di dalamnya. Untuk mendapatkan guru yang berkualitas diperlukan seleksi yang baik. Maka dari itu, untuk mengetahui bagaimana proses seleksi tersebut dilakukan. Seleksi merupakan proses perjuangan dan penentuan siapa yang layak dan tidak layak untuk menempati jabatan disebuah perusahan (Fahmi, 2016).

\section{METODE PENELITIAN}

Tujuan penelitian adalah untuk mengetahui,mendeskripsikan,dan memberikan informasi mengenai seleksi, tupoksi dan pembinaan guru berprestasi di SD Al Irsyad Al Islamiyyah Kota Bekasi. Waktu penelitian dilaksanakan pada bulan Mei sampai dengan Juni 2019dengan responden penelitian terdiri dari kepala sekolah dan guru berprestasi.

Penelitian dilakukan dengan menggunakan metode kualitatif. Penelitian kualitatif adalah penelitian yang menghasilkan prosedur analisis yang tidak menggunakan prosedur analisis statistik atau cara kuantifikasi lainnya. Pengumpulan data penelitian ini terbagi menjadi dua bagian yaitu sumber data primer dan sekunder. Sumber data primer adalah sumber data yang langsung diberikan data kepada pengumpul data. Data primer dalam penelitian diperoleh langsung oleh kepala sekolah, guru-guru, serta pihak yang dianggap memiliki kepentingan pada situasi sosial obyek yang akan diteliti. Sedangkan sumber data sekunder adalah sumber yang tidak langsung memberikan data kepada pengumpul data. Data sekunder yang dimaksudkan adalah data arsip, serta dokumen-dokumen tentang beberapa hal yang terkait dengan kegiatan pendidikan di SD Al Irsyad Al Islamiyyah. 


\section{HASIL DAN PEMBAHASAN}

Seleksi guru berprestasi pada SD Al Irsyad Al Islamiyyah dilakukan melalui observasi awal guru yang harus sesuai dengan standar kompetensi guru dan kiteria penilaian yang sama dengan kemendikbud dalam pedoman guru berprestasi. SD Al Irsyad Al Islamiyyah memiliki 3 prosedur tetap, yaitu seleksi akademik, seleksi administrasi dan seleksi khusus.

Dengan memiliki tahap prosedur awal pada saat seleksi akademik minimal guru memiliki kualifikasi akademik sarjana (S1) dan mengajar sesuai dengan mata pelajaran di sekolah dasar. Seleksi administrasi diantaranya guru harus mengajar ditingkat sekolah dasar dengan mempunyai masa kerja 8 tahun, aktif melaksanakan pembelajaran, disiplin dalam mengajar, tidak pernah dikenai hukuman, memiliki penilaian kinerja guru, bukti partisifasi aktif di masyarakat. Persyaratan khusus (Membuat portofolio, membuat karya tulis ilmiah, Penilaian Kinerja Guru (PKG), laporan hasil PKG dan tugas tambahan guru lainnya, serta menyampaikan video pembelajaran. Seluruh persyaratan seleksi diatas wajib dilengkapi oleh peserta guru berprestasi agar bisa lulus ketahap selanjutnya.

Berdasarkan observasi diperoleh infomasi bahwa dalam pengambilan keputusan penentuan calon guru berprestasi pada tingkat sekolah adalah stakedolders diantaranya pihak yayasan, dan kepala sekolah. Penilaian dilakukan selama tiga bulan. Panitia seleksi terdiri dari kepala sekolah, wakil kepala sekolah dan dibantu oleh komite. Kepala sekolah lalu mengajukan nama-nama atau kandidat guru berprestasi tersebut kepada yayasan, sehingga yayasan akan melakukan penilaian lulus atau tidaknya calon guru berprestasi tersebut untuk menjadi kandidat guru berprestasi tingkat satuan pendidikan.

SD Al Irsyad Al Islamiyyah sangat taat pada setiap peraturan dan prosedur pendidikan. Hal tersebut terjadi karena baiknya kualitas tenaga pendidik itu dilihat dari berbagai segi. Misalnya disiplin kerja dan disiplin mengajar. Sehingga dapat menghasilkan outcome berupa guru yang berprestasi maupun guru yang memiliki kualitas pendidik yang baik. Sekolah dapat dikatakan efektif apabila outcome dari kegiatan organisasi sekolah memenuhi atau melebihi tujuan organisasi.

Dalam pemilihan guru SD berprestasi penilaian dilakukan terhadap aspekaspek sebagai berikut:

Portofolio. Dokumen portofolio beserta bukti-bukti kebenaran, sesuai dengan originalitas data, dan meliputi komponen akademik serta nonakademik.

Video pembelajaran. Penilaian perencanaan dan pelaksanaan pembelajaran dilakukan berdasarkan dokumentasi video pembelajaran. Video pembelajaran yang dinilai meliputi komponen pendahuluan, kegiatan inti, evaluasi, penutup.

Tes tertulis. Penilaian kompetensi guru dilakukan dengan tes tertulis berkaitan dengan kompetensi professional, pedagogik, kepribadian dan social, serta wawasan pendidikan. 
Karya tulis ilmiah. Karya tulis ilmiah yang disusun oleh guru merupakan penilaian tindakan kelas (PTK) sesuai dengan metode tertentu dan sistematika, penulisan sesuai dengan aspek-aspek penilaian karya tulis.

Presentasi Artikel Karya Ilmiah. Penilaian presentasi artikel dilakukan dengan presentasi dan tanya jawab meliputi aspek pemaparan, materi bahasan, sikap dalam presentasi, dan artikel.

\section{Peran Stakeholders dalam Pengembangan Mutu Pendidikan}

Dalam proses mengembangkan kompetensi yang dimiliki oleh setiap guru berprestasi maka yang berperan bukan hanya stakeholder tingkat sekolah saja melainkan juga pemerintah daerah, Lembaga Pengembangan Mutu Pendidikan (LPMP) dan Pusat Pengembangan Pemberdayaan Pendidik dan Tenaga Kependidikan (P4TK)yang membantu mengarahkan dan menjalankan tupoksinya masing-masing.

Adapun peran Pemerintah Daerah (Dinas Pendidikan Kabupaten/Kotamadya dan Provinsi), LPMP dan P4TKdalam peningkatan kualitas guru adalah: Pemerintah daerah bertugas melakukan pembinaan profesionalisme guru dan pemberian beasiswa untuk biaya pendidikan S1, sekaligus dukungan dan bantuan teknis guru.

Selanjutnya, P4TK sebagai unit pelayanan teknis Kemdikbud di daerah, lebih mendukung program peningkatan kualifikasi pendidikan guru dengan melakukan sosialisasi atau pendidikan dan pelatihan bagi guru mata pelajaran sesuai dengan fokus program-program yang diadakan oleh P4TK. Selain melalui dinas pendidikan, ditingkat sekolah, para pengawas juga melakukan sosialisasi melalui forum KKG dan Musyawarah Guru Mata Pelajaran (MGMP) agar guru memenuhi standar kualifikasi pendidikan segera menempuh pendidikan untuk mencapai S1/D4 sehingga bisa mengajukan serifikasi. Adapun LPMP berperan untuk meningkatkan kualifikasi pendidikan guru.

Dari hasil kajian menunjukkan bahwaketigainstitusi tersebut turut berperan dalam peningkatan kualifikasi pendidikan guru, namun bentuk peran dan keterlibatan mereka berbeda satu sama lain. Hal ini sesuai masing dengan kewenangan masing-masing institusi tersebut. Yang harus dilakukan adalah masing-masing institusi melakukan koordinasi, namun tidak secara intensif, koordinasi dilakukan hanya bila diperlukan, misalnya ketika P4TK akan menentukan peserta pendidikan dan pelatihan, P4TK akan berkoordinasi dengan Pemda.

\section{Peran dalam Bimbingan Pembelajaran}

Pemerintah daerah mempunyai peran yang cukup besar, antara lain sebagai berikut: Pertama, pemenuhan 24 Jam mengajar/Minggu.Kedua, terkait dengan upaya untuk menangani guru mengajar tidak sesuai 
(mismatch). Dinas pendidikan menetapkan model guru mata pelajaran. Ketiga, dalam hal pembelajaran Dinas Pendidikan umumnya melaksanakannya dalam berbagai bentuk kegiatan pelatihan, workshop, dan pendampingan terkait dengan materi dan proses/metode pembelajaran, kinerja guru serta peningkatan profesi guru yang berkelanjutan, termasuk pengembangan diri dan publikasi ilmiah.

Peran P4TK dalam pembimbingan pembelajaran lebih pada meningkatkan kemampuan individu guru yang dilaksanakan melalui program untuk meningkatkan kompetensi mengajar (kompetensi pedagogis) para guru. Misalnya melakukan bimbingan pembelajaran melalui pendidikan dan pelatihan (Diklat) jenjang dasar, lanjut, dan tinggi untuk 3 program umum, yakni tentang:1) kebijakan terkini dan nasional, 2) program pokok: materi dan pembelajaran (pakem silabus, RPP, alatevaluasi); dan 3) Penelitian Tindakan Kelas (PTK). Adapun program penunjang, dilaksanakan diklat tentang pengelolaan MGMP, media pembelajaran (IT), atau program lain yang disesuaikan dengan kebutuhan para guru. Selain itu, dilaksanakan pula diklat manajemen (pengawas bidang studi dan kelas serta Kepala Sekolah) dan penguatan kepala sekolah.

\section{Peran dalam Pengembangan Keprofesian Berkelanjutan (PKB)}

Mencakup kegiatan pengembangan diri, pembinaan kolektif, publikasi ilmiah, dan pengembangan karya inovatif. Secara umum, Pemda melakukan upaya-upaya pengembangan keprofesian berkelanjutan bagi guru untuk meningkatkan kompetensinya.

Pertama, pada aspek pengembangan diri, upaya pengembangan diri dalam rangka pembinaan karier dan profesionalisme guru diketahui telah diupayakan oleh Dinas Pendidikan di seluruh lokasi penelitian. Upaya ini berbentuk pengadaan pendidikan dan pelatihan (diklat), workshop, dan seminar, baik terprogram secara regular maupun dilaksanakan secara insidental.

Kedua, berupa pembinaan yang bersifat kolektif, hampir seluruh Dinas Pendidikanberperan dalam mengembangkan gugus KKG dan MGMP untuk melakukan pembinaan karier dan profesionalisme guru melalui berbagai macam kegiatan

Ketiga, publikasi ilmiah, kewajiban memenuhi publikasi ilmiah bagi guru merupakan hambatan terbesar yang dihadapi guru, terlebih bagi guru yang telah mencapai kepangkatan dangolongan.

P4TK ikut berperan melalui Diklat PKG. Melalui KKG dan MGMP program bermutu antara lain tentang: strategi pembelajaran dan materi pembelajaran baru, pendalaman materi, serta pengembangan kurikulum. Diklat pengembangan diri secara khusus di selenggarakan satu tahun satu kali. Selain itu, P4TK ikut serta dalam memfasilitasi guru agar menguasai 
tatacara penulisan karya ilmiah dan PTK serta publikasi melalui diklat baik di P4TK maupun Dinas Kota/Kabupaten dengan memberikan bantuan tenaga widyaiswara dariinstansinya.

Berdasarkan hasil temuan yang didapatkan selama proses pengambilan data maka ditemukan infromasi bahwa setelah calon guru berprestasi melaksanakan seleksi, maka calon guru tersebutakan mendapatkan pembinaan dari Kepala Sekolah. Pengalaman kepala sekolah yang pernah mengikuti lomba guru berprestasi menjadi informasi dan pengalaman lain yang dapat diberikan kepada guru yang akan mengikui seleksi guru berprestasi. Selanjutnya, pengawas dan dinas pendidikan pada wilayah masing-masing memberikan support, pelatihan membuat portofolio, dan seminar sebagai rangkaian kegiatan yang harus di ikuti oleh guru berprestasi. Sedangkan LPMP memberikan pemahaman tentang karya tulis ilmiah dan buku sesuai prosedur sehingga dapat dipublikasikan.

Persyaratan seleksi guru berprestasi yang dilakukan oleh SD Al Irsyad Al Islamiyyah menggunakan tiga prosedur melalui seleksi akademik, administrasi dan khusus yang terdiri dari penilaian portofolio, video pembelajaran, tes tertulis, karya tulis dan presentasi karya tulis ilmiah merupakan serangkaian tes yang memberikan pemahaman kepada calon guru berprestasi untuk menjadi pribadi guru yang memiliki kompetensi professional, dimana guru harus menguasai kompetensi pedagogic, kompetensi kepribadian, kompetensi sosial dan kompetensi professional. Tujuan diadakannya seleksi tersebut sesuai dengan prinsip yang menyatakan bahwa "The Right man in the right place" atau untuk mendapatkannya tenaga kerja yang tepat di dalam posisi yang tepat pula. Seleksi yang dilakukan sesuai dengan pendapat Brian A Jcob yang berpendapat bahwa :

" teacher selection process in public schools Washington, DC. In 2009, the district created a centralized application process to streamline recruitment by filtering out less desirable candidates. After collecting standard information, applicants are askedto complete up to three additional in-depth assessments: (1) written assessments specifically for the subject to assesstheir understanding of teaching content and practice; (2) structured interviews for 30 minutes withdistrict officer; and (3) teaching "auditions" that are observed and evaluated by district employees" (Jacob, 2016).

Peran stakeholder yang menjalankan tugas sesuai dengan tupoksinya tersebut sependapat dengan pendapatnya Elizabeth Murakami and Monika Tornsen yang menyatakan bahwa:

"Principals are expected to support students in their academic achievements, support teachers in preparing to improve their pedagogy, and they are also expected to support families in the community, with the intention of guiding students towards their future. Through schools, principals also model work in 
a democratic environment where principals and teachers prepare" (Murakami \&Törnsén 2015).

Pembinaan dan pengembangan profesionalisme guru yang dilaksanakan melalui berbagai strategi dalam bentuk diklat (pendidikan dan pelatihan) maupun bukan diklat, antara lain ialah: 1) pendidikan dan pelatihan diantaranya adalah program IHT (In-House Training) yang berupa pelatihan yang dilaksanakan secara internal di kelompok kerja guru, pendidikan lanjut yaitu pembinaan profesi guru melalui pendidikan lanjut juga merupakan alaternatif bagi peningkatan kualifikasi dan kompetensi guru, pembinaan internal oleh sekolah yaitu pembinaan yang dilaksanakan oleh kepala sekolah; 2) Seminar yang merupakan kegiatan pembinaan publikasi ilmiah, kemudian ada workshop yang dilakukan untuk menghasilkan produk yang bermanfaat bagi pembelajaran, peningkatan kompetensi, maupun pengembangan karir tersebut sesuai dengan pendapatnya Sudarwan yang menyatakan bahwa pembinaan profesionalisme guru dapat dilakukan melalui pelatihan dan seminar seperti pembuatan media pembelajaran yang dibuat dalam bentuk alat peraga, alat praktikum sederhana, maupun bahan ajar (Sudarwan, 2012).

Pengembangan profesionalisme guru berdampak besar pada proses pengajaran dan parilaku guru di kelas. Youngs menjelaskan 4 model pengembangan profesionalisme guru yaitu teacher's networks, the use of consultants and inter-visitation, students' assesments and school improvement plants(Villegas-reimers, 2003). Model tersebut memberi penguatan kompetensi, keterampilan guru dan berdampak pada pembangunan masyarakat, kontinuitas serta meningkatnya SDM pendidikan. Pada konteks pelatihan guru pendampingan diharapkan dapat membantu dan mendorong menciptakan pemahaman baru terkait bagaimana cara mengajar, memperoleh, ide-ide serta memahami apa dibutuhkan untuk meningkatkan metode pembelajaran (Widyasari \&Yaumi, 2015).

Profesionalisme guru tidak lepas dari proses pembinaan guru baik pembinaan langsung oleh kepala sekolah dan pengawas atau juga oleh Pusatpusat Pengembangan dan Pemberdayaan Pendidikan dan Tenaga Kependidikan (P4TK). Pembinaan kompetensi guru, sangat penting karena perubahan ilmu pengetahuan dan teknologi sangat cepat, sehingga menuntut guru untuk terus menerus "mengabgrid" dirinya sehingga dapat mengikuti atau bahkan membuat suatu rekayasa teknologi yang bermanfaat bagi kehidupan masyarakat luas (Rahman, 2009).

\section{SIMPULAN}

Seleksi guru berprestasi dilakukan melalui disiplin kerja dan disiplin mengajarsehingga dapat menghasilkan outcome yang memiliki kualitas pendidik yang baik. Proses seleksi guru berprestasi terdiri dari seleksi akademik minimal 
sarjana dan memiliki sertifikat pendidik, seleksi administratif yang memberikan penjelasan tentang keaktifan mengajar sebagai guru dengan berbagai bukti pendukungnya, dan seleksi persyaratan khusus yang mewajibkan guru memiliki portofolio, karya tulis ilmiah, penilaian kinerja guru dengan kategori minimal baik, mengikuti tes tertulis, membuat video pembelajaran dan presentasi karya tulis ilmiah. Sedangkan pembinaan guru berprestasi diberikan oleh kepala sekolah pada satuan pendidikan, pemerintah daerah, pengawas, dinas pendidikan, LPMP, Perguruan Tinggi dan P4TK yang masing-masing bekerja sesuai dengan peran dan fungsi yang sudah disepakati.

\section{DAFTAR PUSTAKA}

Villeges, R. (2003). Teacher Profesional Development: an Internasional Review of the Literature, Production

Fahmi, I. (2016). Manajemen Sumber Daya Manusia. Bandung: Alfabeta

Innayatillah, O. A., \& Rusi, R. A. (2016). Pengaruh Kepemimpinan Transformasional Kepala Sekolah terhadap Kinerja Guru di MA Miftahul Huda dan di MA Fathan Mubina. Ta'dibi, 5(2)

Jacob, B. A. (2016). The Power of Teacher Selection to Improve Education. Evidence Speaks Reports

Kompri, K. (2015). Manajemen Penididikan 2. Bandung: Alfabeta

Miles, M. H. (1992). Analisis Data Kualitatif. Jakarta: Universitas Indonesia

Murakami., E., \& Tornesn, M. (2015). Democratic Purpose and Educational Leadership Policies in Sweden and in Texas", Ejurnal of Education Policy, 24(2)

Mustari, M. (2014). Manajemen Pendidikan. Depok: PT. Raja Grafindo

Rahman, A. (2009). Pembinaan Profesional Guru SMK. Jurnal Tabularasa PPS Unimed, 6(1)

Samuel, T. E. (2017). Manajemen Sumber Daya Manusia. CV.R.A.De.Rozarie: Jawa Timur

Sauri, S. (2010). Membangun Karakter Bangsa melalui Pembinaan. Jurnal Pendidikan Karakter

Sudarsana, U. (2014). Pembinaan Minat Baca. Jakarta: Gramedia

Syahputra, F. I., L., \& Agus, P. W. (2018). Sistem Pendukung Keputusan Pemilihan Guru Berprestasi Kota Medan Menerapkan Metode Preferences Selection Index. Konferensi Nasional Teknologi Informasi dan Komputer 2, $147-55$

Syifa, F., Emnis, A. M., \& Rusi, R. A. (2016). Pengaruh Sertifikasi Guru Terhadap Kinerja Guru di SDN Ciawi 1 dan SDN Ciawi 2 Bogor, Jurnal Ta'dibi, 5(1)

Widyasari, W., \& Yaumi, Y. (2015). Evalusi Program Pendampingan Guru SD Dalam Implementasi Kurikulum 2013. Lentera Pendidikan, 17(2) 